\title{
A Standard Terminology and Notation for Fishery Dynamics
}

\author{
By \\ S. J. Holt \\ Food and Agriculture Organization of the United Nations, Rome \\ J. A. Gulland \\ Fisheries Laboratory, Lowestoft, England \\ C. Taylor \\ U.S. Fish and Wildlife Service, Woods Hole, U.S.A. \\ and \\ S. Kurita \\ Tokai Regional Fisheries Research Laboratory, Tokyo
}

\section{Introduction}

In view of the rapid increase in publications dealing with various aspects of fishery dynamics, the need was recognized at the Special Meeting held by the Research and Statistics Committee of the International Commission for the Northwest Atlantic Fisheries (ICNAF) at Biarritz in March 1956, for standardization of the mathematical symbols for the most commonly used quantities. The basis for discussion was a review prepared by GullaND $(1956,1958)$; a system of notation was proposed, and provisionally accepted by the Commission at the 1956 Annual Meeting for use in its publications.

The proposals were next communicated to Dr. Susumu Kurita, of the Tokai Regional Fisheries Research Laboratory, who convened a small group of Japanese scientists to consider them. The group, consisting of: Mr. KURITA (Chairman), Mr. Takeyuki DoI, Mr. Syoiti TanaKa, Mr. Shigeichi Hayashi (Tokai RFRL), Mr. Ichiro Yamanaka (Japan Sea RFRL, Niigata) and Mr. Nobuhiko Hanamura (Hokkaido RFRL, Yoichi), reported its discussions in a paper (KURITA, 1957) submitted to the Joint Scientific Meeting of the International Commission for the Northwest Atlantic Fisheries, the International Council for the Exploration of the Sea, and the Food and Agriculture Organization of the United Nations at Lisbon, May/June 1957. Consideration of this document led the meeting to prepare a report on the matter and to recommend: "that this report be brought to the attention of the Japanese committee, who should be invited to forward their comments to a group consisting of Mr. TAYlor (ICNAF), Mr. Gulland (ICES) and Mr. Holt (FAO). Any change 
Terminology and Notation for Fishery Dynamics

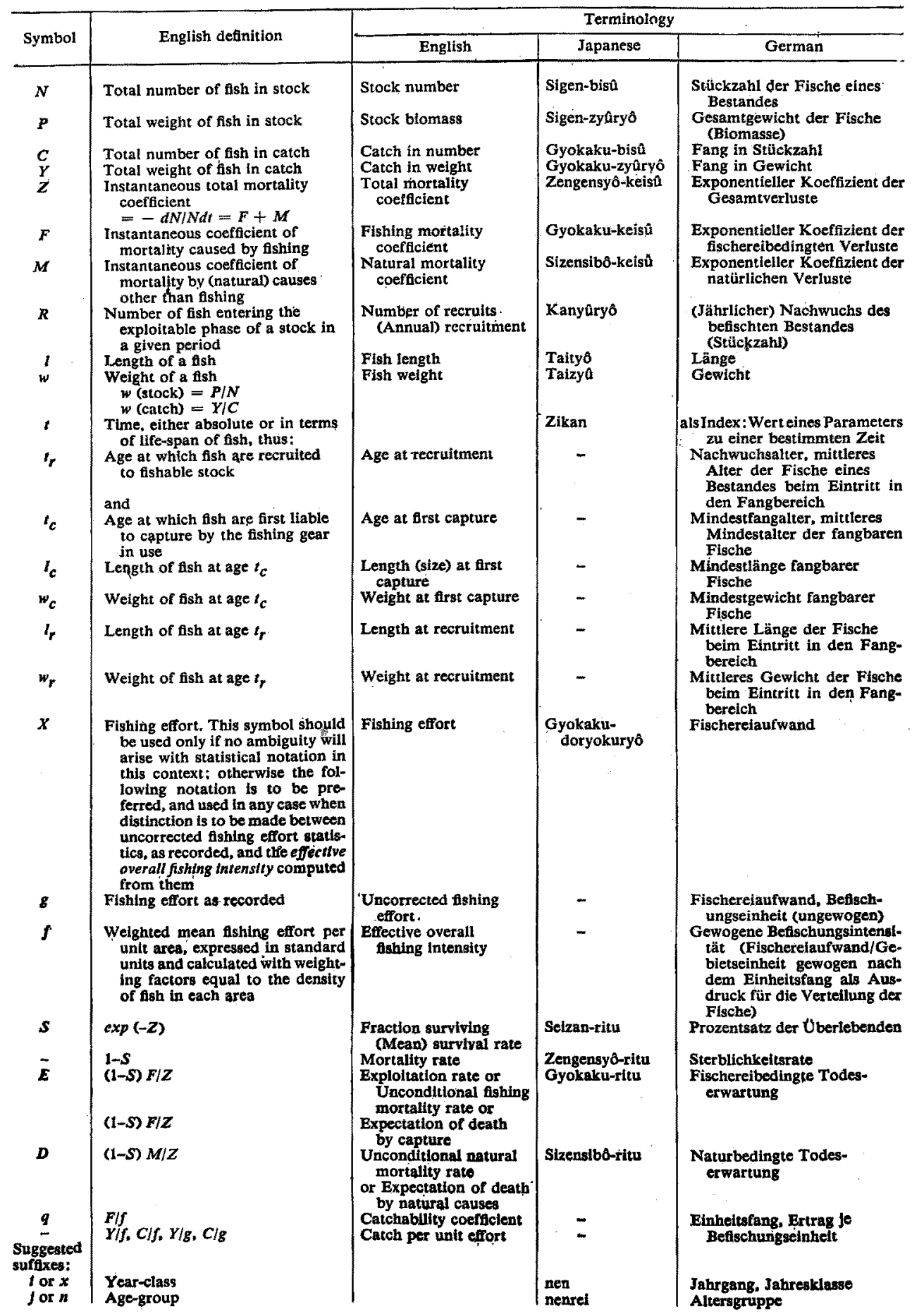


from the Biarritz notation agreed by this group should then be placed before the first convenient meetings of ICNAF and ICES with the strong recommendation that the revised notation should be adopted by all workers in the respective organizations. Meanwhile the group should bring the proposed notation to the attention of workers in areas other than those mentioned above and should take steps to obtain its adoption by other International fishery organizations."

The actions suggested have been taken and the 45th Statutory Meeting of ICES at Bergen 1957, recommended the adoption by its member countries of the notation as finally amended. We believe the result of this exchange of views and ideas is substantial agreement among interested scientists in countries conducting research on the dynamics of fish populations on a notation which, although not free from logical defects, nor conforming wholly with any other commonly used notation, can nevertheless be adopted for the greatest convenience of research workers throughout the world without necessitating complete change in the practices of any one group.

Our recommendations are being made known not only to international fisheries councils and commissions but also to the editors of periodicals publishing papers on fishery dynamics, with the request that they bring the proposals to the attention of their contributors and readers. Just as most journals will accept only contributions written in one of a specified group of languages, it may be that editors will find it possible either to use the standard notation throughout or at least to make it a condition of acceptance of an offered contribution that, if the standard forms are not used, all terms and symbols, be precisely defined. This would make it possible to reduce, by omission of such definitions, the texts of papers in which standards are used.

English was the working language of the Biarritz and Lisbon meetings so that symbols we recommended stood for concepts expressed in that language. Work has, however, begun in preparing lists of equivalent terms in other languages. The Japanese group referred to above submitted to the Lisbon meeting a list of Japanese equivalents, and Drs. G. HeMPEL and D. SAHRHAGE have recently prepared, in collaboration with Professors A. BüCKMANN, J. LUNDBECK, and A. vON BRANDT, a list of terms in German. They have kindly agreed that extracts from their list should be used here, and in the following table the standard symbols are therefore accompanied by equivalent terms in three languages. Steps are being taken to have equivalent lists drawn up in other languages used in international publications, particularly French, Russian, and Spanish. Definition of the derived quantities is made without reference to language by expressing their relations with the fundamental quantities by algebraic formulae.

Estimates of quantities may be symbolized by use of lower case type, except for fishing mortality coefficients and number of fish in stock, when ambiguity might be created with effective fishing intensity, and age-group numbers respectively. Alternatively, the common statistical practice of using a circumflex accent to indicąte an estimate is recommended.

Lastly, mention should be made of typography and the units in which quantities are expressed. It seems to be preferable to print symbols for quantities in italics, reserving roman type for units of measurement thus: -

$$
Y=8.3 \times 10^{9} \mathrm{~g}
$$

This is becoming common practice. We would draw attention to the article in Science (D.R., 1954), which proposes standards for the formation of symbols 
for units which might well be adopted by fisheries workers (see appendix), and we would end with the plea that, at least in publications of an international nature, the centimetre/gramme/second system of units should be used whenever possible as the basis for defining derived units, and for expressing results of research.

\section{References}

D.R., 1954. "Symbols for units of measurement". Sci. N.Y., 120: 1078-80.

GULLAND, J. A., 1956. "Notations in fish population studies". Contribution 2; Working Party No. 3 (Population Dynamics), ICNAF Spec. Meet. Commit. Res. and Statist.,. Biarritz, France, March 1956. (Mimeogr.)

GullaND, J. A., 1958. "Notations in fish population studies" (abstract only) in' "Some problems for biological fishery research and techniques for their solution". Symposium held at Biarritz, France, 1.-10. March 1956. Spec. Publ., ICNAF, 1. (In press.)

KurITA, S., 1957. "A plan for standardisation of terms and notations in population analysis". Conclusions of the Special Committee which met in Tokyo, on 4. December 1956. Paper 6, Joint Scientific Meeting of ICNAF/ICES/FAO, Lisbon, Portugal, May 1957, (Mimeogr.)

\section{Appendix}

Proposed rules for construction and use of symbols for units of measurements (adapted from D. R., (1954)).

1. The symbol preferably should consist of two or three letters and never more than four.

2. The symbol preferably should consist of the first two or three letters of the name of the unit.

3. Preferably there should be only one symbol for a particular unit.

4. Periods (full points), should be omitted from symbols (with the exception of "in." for "inch").

5. The symbol for a combining form denoting a multiple or sub-multiple should be a single letter, thus "k" for "kilo-"

6. Symbol for the unit should be set in roman type.

7. Abbreviated unit symbols should be used only when they are preceded by a numerical value, a symbol for the quantity, or when they appear in headings of tables or crowded text, in which cases the unit symbol is enclosed in parentheses.

8. Standard signs should be used to indicate all mathematical operations with unit symbols, thus division should be indicated by a solidus, a negative exponent or shown in the ordinary fractional form, but the symbol "p" for "per" should not be used, thus: "C/F" or "C.f-1" are preferable to "C.p.u.e." or "Cpf" for "catch per unit effort".

Hyphens should only be used to separate parts of a single unit symbol and not to indicate multiplication, thus: "ST ton hours" is preferable to "S/T ton-hours" for "the product of tonnage and hours fished by steam trawlers". 